\title{
IMPACT OF VARYING THE NOZZLE STAND - OFF DISTANCE ON CUTTING TEMPERATURE IN TURNING OF EN-31 STEEL WITH MINIMUM QUANTITY LUBRICATION
}

\author{
Ajay Kumar ${ }^{1}$, Gurpreet Singh ${ }^{2}$, Simranpreet Singh Gill ${ }^{3}$ \\ ${ }^{1},{ }^{2}$ Lecturer, ${ }^{3}$ Assistant Professor, Department of Mechanical Engineering, \\ ${ }^{1,2}$ Rayat Polytechnic College, Rail Majra, S.B.S Nagar, Punjab, India, ${ }^{3}$ Beant College of Engineering and Technology, \\ Gurdaspur-143521, India, eraj_sharma@rediffmail.com,gssingh410@gmail.com,ritchie_223@yahoo.com
}

\begin{abstract}
Tool wear is a natural phenomenon in all metal cutting operations due to high friction at tool work interface, which affect the tool life, product quality and accuracy of work. For minimizing the friction at tool work interface the cutting fluids or lubricants are used for cooling and lubrication, hence improvement in machining efficiency. But if the quantity and quality of lubricants are unattended or underestimated then it creates problems like soil, water, environmental pollution and also makes the machining process uneconomical. The different cooling and lubrication techniques have been developed today. So it is necessity of present day scenario of machining to work with technology which would not degrade the environment, face the competition and have better quality of products. Different research shows that conventional Flood lubrication is limited by health hazards, misting and sometime uneconomical as compared to other techniques, due to its high discharge rate of fluid. These problems have been overcome by using dry machining. Studies shows that dry machining also becomes non efficient and uneconomical during cutting of harder materials at higher cutting speed, feed and depth of cut, although it is environmental friendly and economical at particular machining level. So to minimize all these Problems of health hazards, non-economy, intense tool wear in case of flood cooling and dry machining, the minimum quantity lubrication (MQL) has been applied in this present research. The effect of varying the nozzle stand-off distance and lubricant pressure have been considered in this study, to find out the best results in terms of cutting temperature. The experimentation has been conducted during turning of EN-31 Alloy Steel with minimum quantity lubrication at flow rate of $150 \mathrm{ml} / \mathrm{hr}$ having vegetable based oil. The temperature has been measured by $K$-type thermocouple. The vegetable oil has been selected due to its environmental friendly behavior and does not produce health hazards, like mineral oil during flood lubrication.
\end{abstract}

Index Terms: Tool wear, Flood lubrication, Dry machining, Minimum quantity lubrication, Nozzle stand-off distance

\section{INTRODUCTION}

High production machining of harder material generates high cutting zone temperature, intense tool wear, high cutting forces and sometimes poor quality of machining. Such effects cannot be eliminated completely, due to higher friction at tool work interface but can be minimized by cooling and lubricating the tool. For this various methods of cooling and lubricating the tool have been developed. The application of different cooling and lubrication methods depends upon the type of machining operation, work material and cutting parameters. Different cutting operation requires different cutting fluids due to their different tool work interaction. The flood lubrication has been applied since the need of lubrication had been aroused. The use of cutting fluid reduces the cutting temperature, tool wear and surface roughness, if applied in optimum amount and in best way. The role of quantity and quality of lubricant play important role in reducing environmental pollution and enhancing the machining performance. But today's flood lubrication technique has become problematic, because of strict rules regarding the prevention of environmental pollution. In this technique high flow rate of cutting fluids leads to environmental degradation like soil pollution, water pollution, health hazards and most important wastage disposal of cutting fluids. Recycling cost in case of flood lubrication also require addition set up which adds in cooling cost of flood lubrication. Several developing countries have banned the use of flood lubrication and dry machining is major concern due environmental friendly behaviour. Several studies show that dry machining has also been limited up to particular machining parameters levels and materials because during dry cutting of harder material at higher cutting speed leads to higher cutting temperature which effect the tool life as well as product quality. Now the question arises, which system should be selected? Either flood lubrication or dry machining because both have their own advantages and disadvantages.

Today's machining scenario is facing competitiveness, environment strict rules and demands higher production 
volume, better product quality and economical machining. So there is challenging Task for the researcher to manufacture the product with a process, which would not effects the environment and also not limited bad quality of machining at higher cutting speed. Because machining without using cutting fluid leads to several drawbacks likes dimensional inaccuracy, thermal damage of tool, more cutting power and lower tool life. Which make this system objectionable, although it is environmental friendly. The possible solutions for this may be the use of less quantity of lubricants i.e. Minimum quantity lubrication or Near Dry machining. In this technique the low quantity of cutting fluid assisted by pressurized air is used for cooling and lubrication purpose. The flow rate of cutting fluid is typically about $50-500 \mathrm{ml} / \mathrm{hr}$ or sometimes less. Several studies have been conducted by different researchers, using minimum quantity lubrication for different machining operation for reducing the health hazards, cost of lubricant, wastage disposal, cooling cost and environmental pollution. But less focus have been attention on the effect of varying the nozzle distance from the cutting zone and lubricant pressure during machining. So there was a need of study which would consider this parameter for finding the best nozzle distance from cutting zone in terms of cutting temperature and surface roughness during turning operation using minimum quantity lubrication. Because by varying the nozzle distance and lubricant pressure, the drop distribution to cutting zone changes, which effect the cutting temperature, tool wear, surface roughness and cutting forces, hence variation in machining performance results.

Dhar, N.R et al [3] has experimentally investigated the effect of Minimum Quantity of Lubrication (MQL) by vegetable oilbased cutting fluid on machinability of steel, the result obtained from this study using uncoated carbide tool i.e. MQL systems enabled reduction in average chip-tool interface temperature up to $10 \%$. Dhar N. R. et al [1] has studied the effects of MQL on temperature, force, tool wear and product quality in turning AISI 9310 steel and experimental results shows that MQL with the present technique has reduced flank wear and cutting forces by about $5 \%$ to $15 \%$. Surface finish and dimensional accuracy has been improved mainly due to reduction in friction at tool chip interface by the application of MQL. Dhar et al. [2] has experimentally investigated the Effect of Minimum Quantity Lubrication (MQL) on Tool Wear, Surface Roughness and Dimensional Deviation in Turning of AISI-4340 Steel, result obtained from this investigation suggested that MQL machining is better than that of dry and conventional flood cutting because MQL provides the benefits mainly by reducing the cutting temperature, which improves the chip-tool interaction and maintains sharpness of the cutting edges. Chaudhary S. M. A. et al. [6] has experimentally investigated the Effect of minimum quantity lubricant on temperature, chip formation and cutting force in turning of medium carbon steel. The MQL has been provided in the form of spray using vegetable oil. The result obtained from this experiment shows $20 \%$ reduction in average chip-tool interface temperature and 5\% to $20 \%$.reduction in cutting forces.

Kamruzzaman M. et al. [8] experimentally investigated the effects of High-Pressure Coolant (HPC) jet in machining of $42 \mathrm{Crmo} 4$ steel by uncoated carbide inserts. The main objective of this research was to evaluate the effectiveness of high-pressure coolant in improving the cutting parameters on harder work material.

Thamizhmanii, S. et al. [4] experimentally investigated the effect of minimum quantity lubrication on Inconel 718 on a vertical milling machine with super hard cobalt tool. The result obtained from this experiment i.e. total length of travel by super cobalt cutting tool in MQL condition is higher than that in dry cutting.

Abhang L.B et al. [5] has experimentally investigated the performance of MQL machining of alloy steel with $10 \%$ boric acid by weight mixed with SAE- 40 base oil during turning of EN-31 steel using tungsten carbide cutting tool. Minimum quantity lubricant has reduced the chip-tool interface temperature by 20 to $30 \%$ in this study. Kuram E. et al. [7] has studied the Effects of the Cutting Fluid Types and Cutting Parameters on Surface Roughness and Thrust Force on AISI304 austenitic stainless steel with HSSE tool with raw and refined sunflower oil and two other commercial cutting fluids for evaluation of thrust force and surface roughness during drilling of AISI 304 stainless steel and experimentally observed that Lower thrust force values were obtained with SCF-I and the least thrust force was achieved at spindle speed of $720 \mathrm{rpm}$. at a feed rate of $0.12 \mathrm{~mm} / \mathrm{rev}$.

Park K.E et al. [11] has conducted a study on droplet and their distribution for minimum quantity lubrication in milling operation by using CLSM technique for 3D characterization and volume measurement of drops. The EDA algorithm has been used in this study for droplet distribution in milling operation using minimum quantity lubrication. The experimental results shows the as the nozzle distance increases the surface area covered by droplet decreases and also the droplet size is smaller at higher than as compared to lower pressure. This study has confirmed that nozzle distance should be less than $50 \mathrm{~mm}$ and for higher pressure the smaller nozzle distance is required.

Hadad M.J et al. [9] has experimentally investigated the temperature and energy partition in minimum quantity lubrication during grinding operation having $100 \mathrm{Cr} 6$ as a work material. The temperature has been measured by embedded Ktype thermocouple. The experimental result has proved that the MQL grinding by oil has reduced the $7-10 \%$ energy as compared to dry grinding.

The review of the literature suggests that minimum quantity lubrication provides several benefits in machining. But less 
focus have been attention on the effect of varying the nozzle distance from the cutting zone and lubricant pressure during turning operation. So there was a need of study which would consider this important parameter for finding the best nozzle distance from cutting zone in terms of cutting temperature turning operation using minimum quantity lubrication. This is also the main objective of the present work during machining of EN-31 steel at industrial speed-feed condition by tungsten carbide insert with vegetable based oil.

\section{EXPERIMENTAL SETUP}

Experiments have been carried out by plain turning a $80 \mathrm{~mm}$ diameter and $800 \mathrm{~mm}$ long rod of EN-31 steel on powerful and rigid lathe (HMT, INDIA, 10hp) at different cutting velocities, and feeds under dry and minimum quantity lubrication (MQL) conditions. The machinability characteristic of work material mainly in term of cutting temperature has been investigated by varying the nozzle distance. The ranges of the cutting parameters have selected based on the basis of tool manufacturer recommendation mentioned in their catalogues and as per industrial expert advices. The temperature has been measured by standard K- type thermocouple wires inserted in the hole drilled on the cutting insert by EDM drilling having diameter of $1 \mathrm{~mm}$. The distance of drilled hole is $0.8 \mathrm{~mm}$ from nose radius. The MQL jet has been supplied at pressure of 5 bars through the nozzle at rake face near to the cutting zone at an appropriate angle. The experimentations have been conducted by varying the nozzle distance from 15, 30 and $55 \mathrm{~mm}$ having same cutting parameters in each case and correspondingly values of Cutting temperature has been noted. The first phase experimentation has been conducted at $0.5 \mathrm{~mm}$ depth of cut having $78 \mathrm{~mm}$ job diameter and second phase has been conducted at $1 \mathrm{~mm}$ depth of cut having $76 \mathrm{~mm}$ job diameter.

The nozzle distance has been varied in both case, so total number of experiments are 84 i.e. 42 in first case and 42 in second case. The detail of experimentation has been given in table no. 1-2. The results obtained from experimental work have been presented in the form of graphs for the comparison purpose and also to find out the best nozzle distance from the cutting zone. The MQL jet is mainly focused on the rake face of tool in this present study. There has been variation of Cutting temperature and Surface roughness during variation of nozzle distance and depth of cut. The cutting temperature has been measured in each case with the help of Standard K-type thermocouple for the 30 seconds during cutting operation. The length of work piece is equally distributed among all experiments for measurement of cutting temperature and surface roughness in both cases.

\begin{tabular}{|c|c|c|}
\hline $\begin{array}{l}\mathrm{Sr} \\
\mathrm{No}\end{array}$ & Item & Description \\
\hline 1 & Machine Tool & $\begin{array}{l}\text { Lathe Machine (Hindustan } \\
\text { Machine Tool, INDIA) } 10 \mathrm{hp}\end{array}$ \\
\hline 2 & Work Specimen & $\begin{array}{l}\text { EN-31 Alloy Steel, Size: } \varphi 80 \\
\text { X } 1000 \mathrm{~mm}\end{array}$ \\
\hline 3 & Cutting tool (insert): & SNMG120408 \\
\hline 4 & Tool holder & PSDNN 2525M12 \\
\hline 5 & $\begin{array}{l}\text { Working } \quad \text { tool } \\
\text { geometry }\end{array}$ & $\begin{array}{l}-70,-70,70,70,450,450,0.8 \\
\mathrm{~mm}\end{array}$ \\
\hline 6 & $\begin{array}{l}\text { Cutting velocity } \\
(\mathrm{Rpm})\end{array}$ & $\begin{array}{l}142,320,500,640,800 \text { and } \\
1000\end{array}$ \\
\hline 7 & Feed rate & 0.063 and $0.088 \mathrm{~mm} / \mathrm{rev}$ \\
\hline 8 & Depth of cut & 0.5 and $1 \mathrm{~mm}$ \\
\hline 9 & MQL supply & $\begin{array}{l}\text { Vegetable Oil (Soybean oil) } \\
150 \mathrm{ml} / \mathrm{hr} \text { at } 5 \mathrm{bar}\end{array}$ \\
\hline 10 & $\begin{array}{l}\text { Distance } \\
\text { nozzle }(\mathrm{mm})\end{array} \quad$ of & 15,30 and 55 \\
\hline 11 & Thermocouple & $\mathrm{K}$ - type (-25 to $12000 \mathrm{C})$ \\
\hline 12 & Air Compressor & Single phase motor driven \\
\hline
\end{tabular}

Table-1: Detail of experimentation

Table-2: Experimental conditions for phase 1 and 2 


\begin{tabular}{|l|l|l|l|l|l|}
\hline $\begin{array}{l}\text { Sr } \\
\text { No } \\
\cdot\end{array}$ & $\begin{array}{l}\text { Cuttin } \\
\text { g } \\
\text { Speed } \\
(\text { Rpm) }\end{array}$ & $\begin{array}{l}\text { Feed } \\
\text { Rate } \\
(\mathrm{mm} / \mathrm{r} \\
\text { ev) }\end{array}$ & $\begin{array}{l}\text { Nozzle } \\
\text { distance } \\
\text { in 1st } \\
\text { case } \\
(\mathrm{mm})\end{array}$ & $\begin{array}{l}\text { Nozzle } \\
\text { distance } \\
\text { in 2nd } \\
\text { case } \\
(\mathrm{mm})\end{array}$ & $\begin{array}{l}\text { Nozzle } \\
\text { distance } \\
\text { in 3rd } \\
\text { case } \\
(\mathrm{mm})\end{array}$ \\
\hline 1 & 142 & 0.063 & 15 & 30 & 55 \\
\hline 2 & 200 & 0.063 & 15 & 30 & 55 \\
\hline 3 & 320 & 0.063 & 15 & 30 & 55 \\
\hline 4 & 500 & 0.063 & 15 & 30 & 55 \\
\hline 5 & 640 & 0.063 & 15 & 30 & 55 \\
\hline 6 & 800 & 0.063 & 15 & 30 & 55 \\
\hline 7 & 1000 & 0.063 & 15 & 30 & 55 \\
\hline 8 & 142 & 0.088 & 15 & 30 & 55 \\
\hline 9 & 200 & 0.088 & 15 & 30 & 55 \\
\hline 10 & 320 & 0.088 & 15 & 30 & 55 \\
\hline 11 & 500 & 0.088 & 15 & 30 & 55 \\
\hline 12 & 640 & 0.088 & 15 & 30 & 55 \\
\hline 13 & 800 & 0.088 & 15 & 30 & 55 \\
\hline 14 & 1000 & 0.088 & 15 & 30 & 55 \\
\hline 14 & 1000 & 0.088 & 15 & 30 & 55 \\
\hline
\end{tabular}

\section{RESULTS AND DISCUSSIONS}

During machining of ductile materials, heat is generated, Firstly due to shear and plastic deformation in the primary deformation zone, secondly due to deformation and sliding at chip-tool interface and thirdly due to Friction at work-tool interfaces. Due to all these sources the maximum temperature is produced at tool chip interface and as a result this high degree temperature impacts the Cutting forces, Surface roughness, Tool wear and tool life. Therefore, attempts have been made to reduce this cutting temperature by the application of cutting fluids in past as a flood lubrication. Initially flood lubrication was acceptable due to low production rate and less pollution, although it require high flow rate of lubricant. But in this present study MQL with Soybean oil has been used for cooling and lubrication purpose because Conventional cutting fluid application cannot cool and lubricate tool effectively at the chip-tool interface where the temperature is maximum because it does not reaches efficiently in cutting zone, but scatter nearby thus reduces its cooling ability. The area of cutting zone is very small as compared the area at tool work interface seen visually. On the other hand high discharge rate in case of flood lubrication forms the layer nearby cutting zone reduces the heat transfer rate. So there must be a system which would have high heat transfer rate in cutting zone as compared to flood lubrication.

Fig-1: Schematic diagram of experimental set up
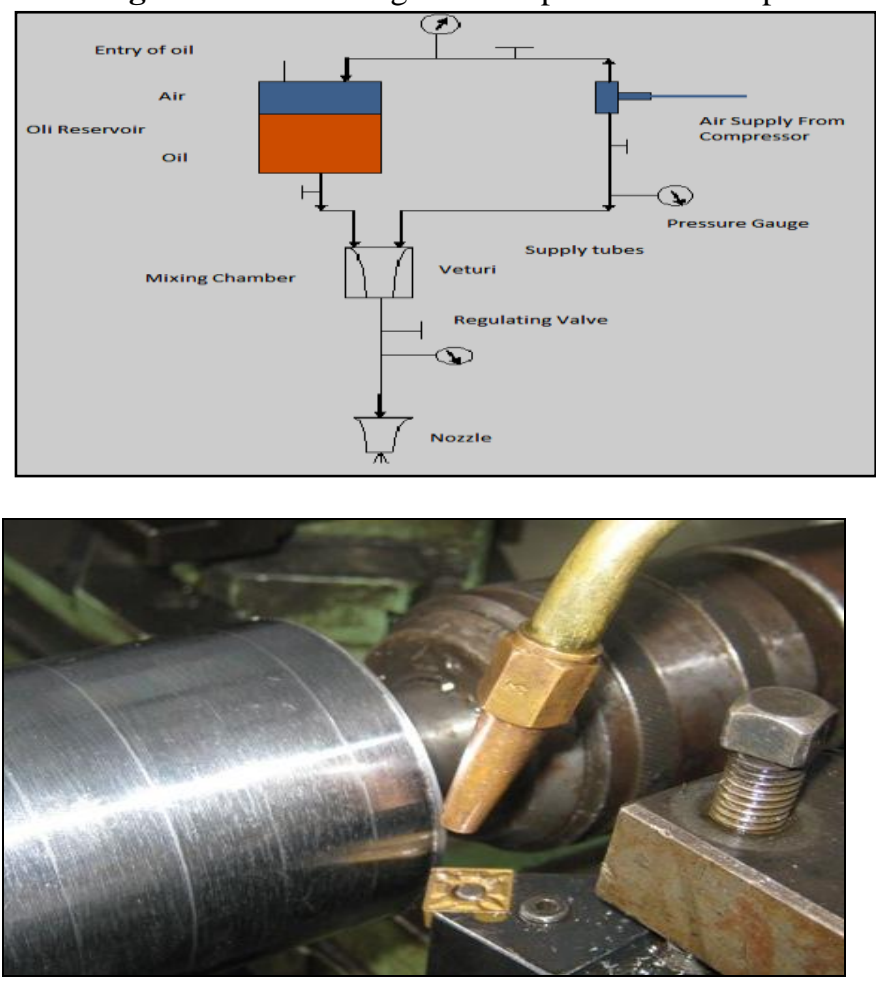

Fig-2: Photographic view of experimental set up

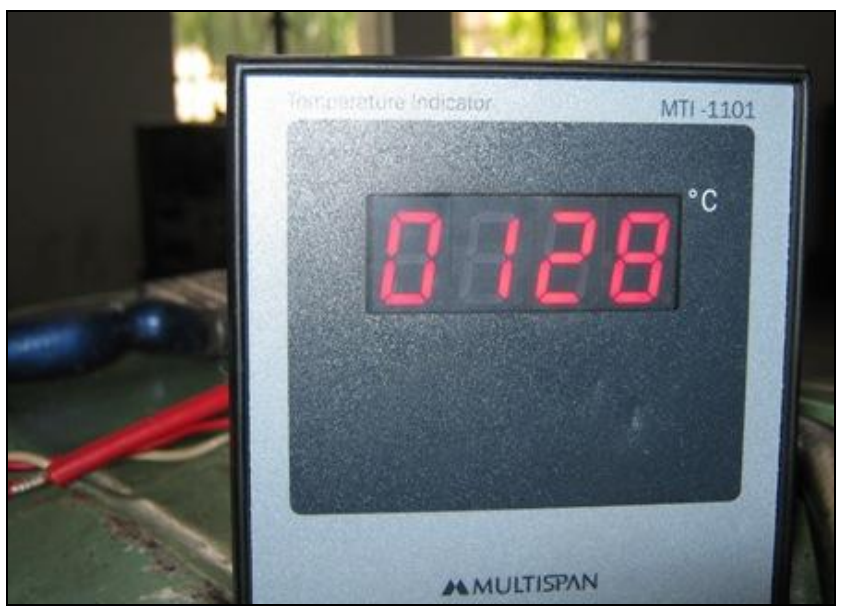

Fig-3: Photographic view of digital temperature indicator

In present work of application of MQL in the form of jet targeted at rake face by varying distance has reduced the cutting temperature as compared dry machining because of efficient cooling and lubricity of vegetable oil. This may be possible because of evaporative cooling action of air assisted 
jet, Cutting and healing action of MQL Fluid as well as by other causes. However, it has been observed that MQL by Soybean oil jet in its present way of application has reduced the average cutting temperature by about $5 \%$ to $12 \%$ depending upon the levels of cutting parameters and distance of nozzle from cutting zone. As shown in Fig 4 and 5 the maximum cutting temperature has been recorded at $55 \mathrm{~mm}$ nozzle distance from the cutting zone and least cutting temperature has been recorded at $30 \mathrm{~mm}$ nozzle distance. When nozzle has been placed at $15 \mathrm{~mm}$ away from cutting zone then recorded temperature is more than the temperature recorded at $30 \mathrm{~mm}$ nozzle distance.

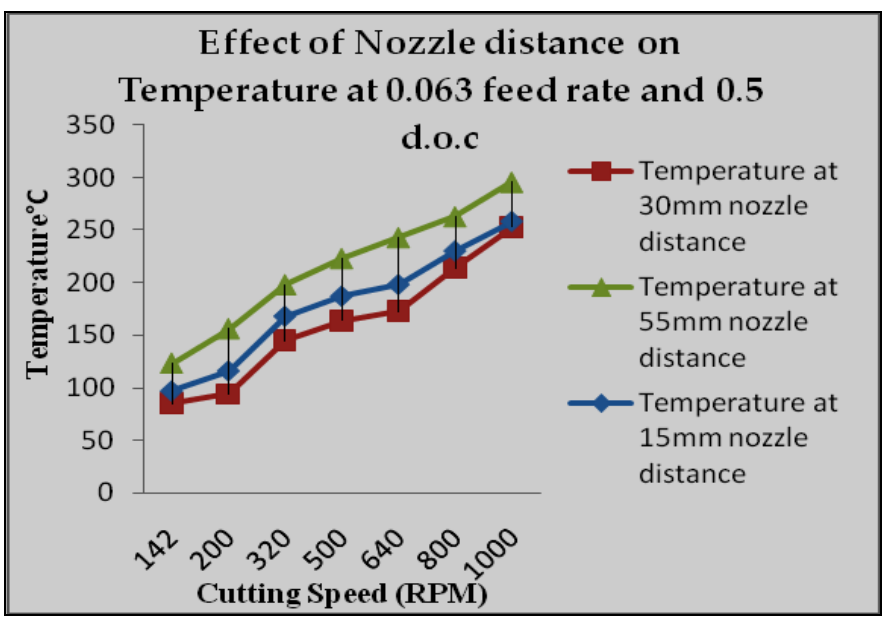

Fig-4: Effect of nozzle distance on cutting temperature at 0.5 doc

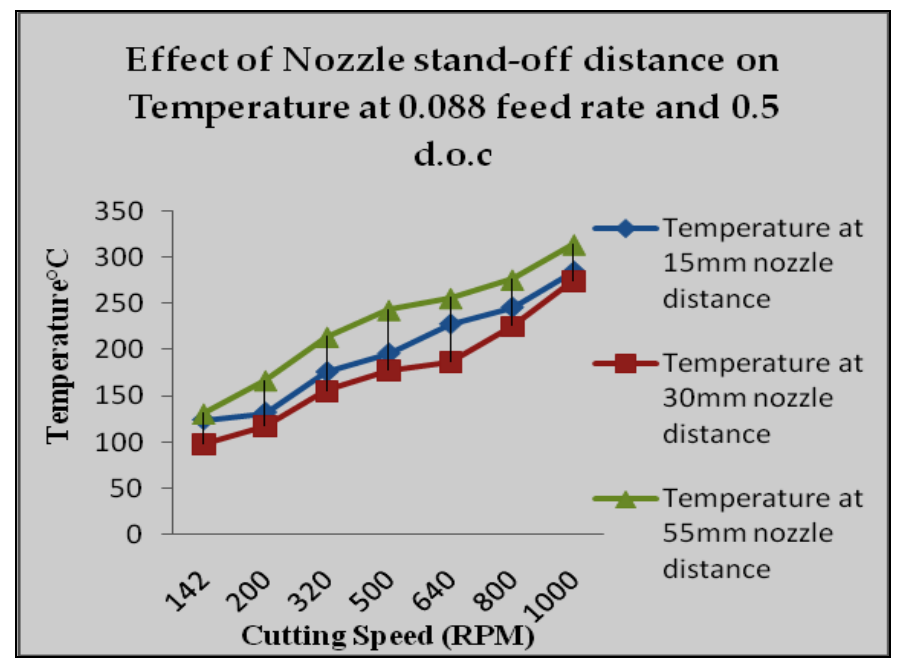

Fig-5: Effect of nozzle distance on cutting temperature at 0.5 doc

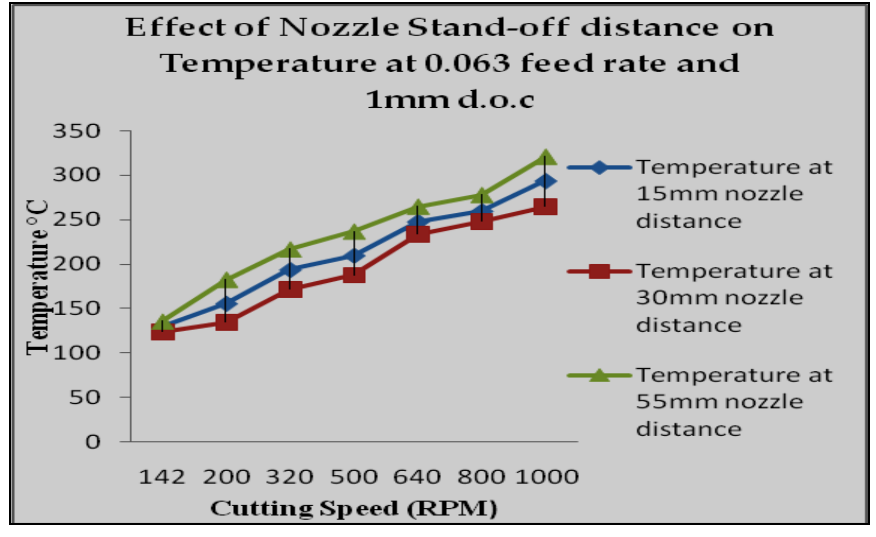

Fig-6: Effect of nozzle distance on cutting temperature at $1 \mathrm{~mm}$ doc

The possible reasons for this may be due to spreading of MQL-Jet's drop distribution into the cutting zone, which is very small as compared to size of drop. The drops issued from the MQL-jet strike at high velocity at tool chip interface, where workpiece is already rotating at high rpm so the drop after striking the workpiece spreads into the surrounding and as a result less cooling effect, when nozzle is placed at $15 \mathrm{~mm}$ nozzle distance. Also the distance is so small that the issued jet would not attain its effective velocity and shape in this short interval of time and would not cool or lubricate the tool effectively. On the other hand when nozzle has been placed at $55 \mathrm{~mm}$ distance, then this distance is so large that issued jet's drops does not (reaches) penetrate into the cutting zone and losses its effectiveness as compared to the $30 \mathrm{~mm}$ stand-off distance.

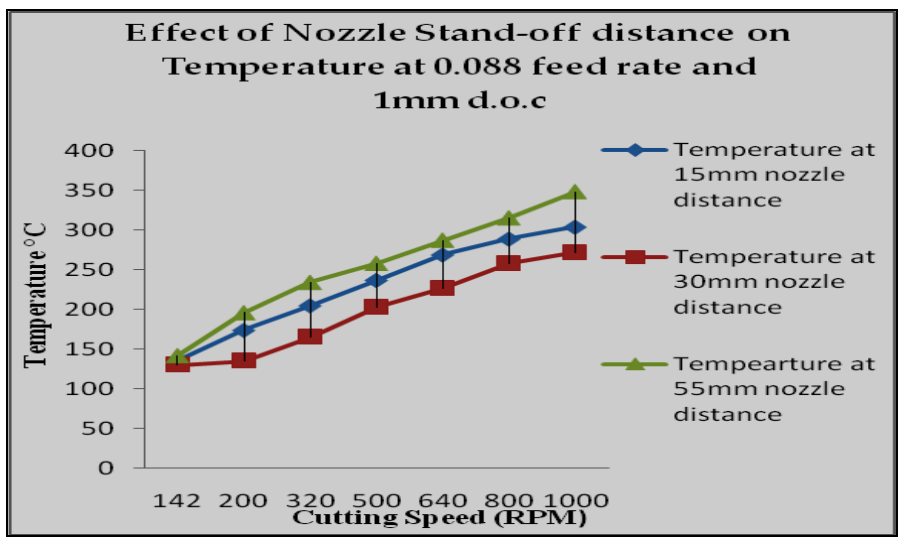

Fig-7: Effect of nozzle distance on cutting temperature at $1 \mathrm{~mm}$ doc

\section{CONCLUSIONS}

The main objectives of present investigation were to find out the influences of varying the nozzle stand- off distance on cutting temperature. The cutting temperature has following relations with stand-off distance during machining. 
1. The maximum cutting temperature has been recorded at $55 \mathrm{~mm}$ nozzle stand-off distance. This is $10-15 \%$ more than 30mm nozzle stand-off distance.

2. When Nozzle has been placed at $15 \mathrm{~mm}$ stand-off distance then the cutting temperature is $5-8 \%$ more than $30 \mathrm{~mm}$ nozzle stand- off distance.

3. The influence of nozzle stand-off is nearly equal to the influence speed rate on cutting temperature during more than 30mm stand-off distance.

4. The lowest temperature has been recorded during $30 \mathrm{~mm}$ stand of distance because of uniform distribution of MQL jet's drops distribution to the cutting zone, which may be not possible during other stand of distances and hence more temperature.

5. MQL by vegetable oil also protects environment pollution by discharging reduced amounts of fumes, mist, oxides during cutting and also reduce health hazards.

\section{REFERENCES}

[1] Dhar, N.R and Khan, M. M. A. (2006), "A study of effects of MQL on temperature, force, tool wear and product quality in turning AISI 9310 steel" Net Fieldwise Seminar on Manufacturing and Material Processing, Pages 30-35, issue(2), 2006.

[2] Dhar, Nikhil Ranjan., Islam, Sumaiya and Kamruzzaman, Mohammad, (2007), "Effect of Minimum Quantity Lubrication (MQL) on Tool Wear, Surface Roughness and Dimensional Deviation in Turning AISI-4340 Steel" G.U. Journal of Science, Volume 20(2), Pages 23-32.

[3] Dhar, N. R., Islam, M. W. (2005), "The influence of Minimum Quantity of Lubrication (MQL) by vegetable oil-based cutting fluid on machinability of steel, International Conference on Mechanical Engineering, Pages 1-5.

[4] Thamizhmanii, S., and Hasan, R. S. (2009), "A study of minimum quantity lubrication on Inconel 718 steel", Archives of Material Science and Engineering, Volume 39, Pages 38-44, September 2009.

[5] Abhang, L B., Hameedullah, M. (2010), "Experimental Investigation of Minimum Quantity lubricants in Alloy Steel Turning", International Journal of Engineering Science and Technology, Volume 2(7), Pages 3055 3053, 2010.

[6] Chaudhary, S. M. A., Dhar, N. R. and Bepari, M. M. A. (2007) "Effect of Minimum Quantity Lubricant on Temperature Chip and Cutting Force in Turning Medium Carbon Steel, International Conference on Mechanical Engineering, ICME (2007), December 2007

[7] Kuram, E., Ozcelik, B., Demirbas E and Sik, E. (2010), "Effects of the Cutting Fluid Types and Cutting Parameters on Surface Roughness and Thrust Force", Proceedings of the World Congress on Engineering, Volume II, July 2010.
[8] Kamruzzamam, M and Dhar, N.R (2008), "The effect of high Pressure Coolant (HPC) Jet in Machining of 42CRMO4 Steel by Uncoated Carbide Inserts", Journal of Mechanical Engineering, Volume ME 39 (No. 2), Pages 71-77, December 2008.

[9] Hadad, M.J., Tawakoli, T., Sadeghi, M.H., and Sadeghi, B. (2012), "Temperature and energy partition in minimum quantity lubrication-MQL grinding process" International Journal of Machine Tools \& Manufacture, Vol. 54-55(2012), pp.10-17

[10] Tawakoli, T., Hadad, M.J., Sadeghi, M.H.(2010), "Influence of oil mist parameters on minimum quantity lubrication - MQL grinding process" International Journal of Machine Tools \& Manufacture, Vol.50 (2010), pp. 521-531.

[11] Park , Kyung-Hee., Yume , Jorge Olortegui., Yoon, Moon-Chu., and Kwon Patrick.(2010) "A study on droplet sand their distribution for minimum quantity lubrication (MQL)" )" International Journal of Machine Tools \& Manufacture ,Vol 50 (2010),pp. 824-833

\section{ACKNOWLEDGMENTS}

The work presented in this paper is the outcome of thesis done by the first author during Master of Technology (Production Engineering) Degree under the guidance of third author. The authors are thankful to faculty and staff of Beant College of Engineering and Technology, Gurdaspur (India) for support and encouragement.

\section{BIOGRAPHIES}

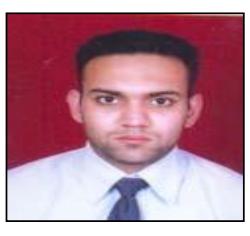

Ajay Kumar is currently working as Lecturer in Department of Mechanical Engineering at Rayat Polytechnic College, Rail Majra, Punjab. After completing his B.Tech in Mechanical Engineering, currently he is doing M.Tech at Beant College of Engineering and Technology, Gurdaspur (India).

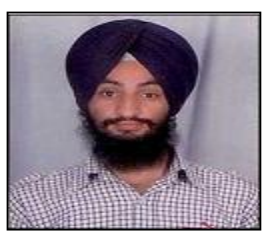

Gurpreet Singh is currently working as a Lecture in Department of Mechanical Engineering at Rayat Polytechnic College, Rail Majra, Punjab, India. He has obtained his $M$ Tech degree in Production Engineering from PTU Jalandhar. He has Published numbers of papers in national and international conferences.

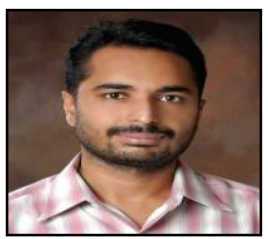

Simranpreet Singh Gill is currently working as Assistant Professor in Department of Mechanical Engineering at Beant College of Engineering and Technology, Gurdaspur (India). His area of research work is sustainable manufacturing technologies. He has published many research papers in reputed international journals. 